\title{
MULTIMEDIA LEARNING UNTUK SEKOLAH DASAR
}

\author{
Bambang Nurdewanto $^{1}$ ), Elta Sonalitha ${ }^{2}$ ), Rusdijanto ${ }^{3)}$, Adi Sunarwan ${ }^{4)}$ \\ ${ }^{1,2,)}$ Fakultas Teknologi Informasi Universitas Merdeka Malang \\ ${ }^{3,4)}$ Fakultas Teknik, Universitas Merdeka Malang. \\ email: elta.sonalitha@unmer.ac.id
}

\begin{abstract}
Abstrak
Kurikulum 2013 mengedepankan konsep Tematik, Pembelajaran tematik adalah pembelajaran terpadu yang menggunakan tema untuk mengaitkan beberapa mata pelajaran sehingga dapat memberikan pengalaman bermakna kepada peserta didik. Tema adalah pokok pikiran atau gagasan pokok yang menjadi pokok pembicaraan. Masalah yang ditemukan di SDI Mohammad Hatta dan SDN TunjungSekar I adalah pemahaman siswa terhadap satu tema yang dijelaskan guru di papan tulis bisa saja diulang untuk ke tahap pemahaman, kurangnya pemanfaatan media dalam proses dokumentasi pembelajaran serta kondisi jika siswa yang berhalangan masuk dikarenakan ijin, bisa saja tertinggal dalam mengikuti pelajaran, juga siswa yang terlambat memahami materi akan kesulitan untuk memahami materi berikutnya yang berkaitan. Hal ini menyebabkan capaian belajar siswa kurang maksimal.

Pembelajaran berbasis multimedia dikembangkan sebagai solusi permasalahan mitra ini berupa Video Pembelajaran untuk pembelajaran model Tematik. Tujuan pengabdian ini adalah untuk memberi pelatihan kepada guru untuk dapat membuat video animasi pembelajaran melalui media audio video dan memasarkan video animasi pembelajaran tersebut melalui web marketing
\end{abstract}

Kata Kunci : Multimedia, Video Animasi, Web Marketing, E-Learning

\section{PENDAHULUAN}

Mahadewi, dkk. (2012:4) menyatakan "media video pembelajaran dapat diartikan sebagai segala format media elektronik yang digunakan untuk merangsang pikiran, perasaan dan minat siswa untuk belajar melalui penanyangan ide atau gagasan, pesan dan informasi”. Pernyataan diatas mengungkapkan bahwa sebuah video pembelajaran mampu menumbuhkan motivasi belajar siswa karena di dalam video terdapat animasi-animasi yang menarik perhatian siswa.

Video pembelajaran juga mampu memperjelas makna bahan pengajaran sehingga mudah dipahami oleh siswa. Pemahaman terhadap bahan pengajaran yang bersifat abstrak/kompleks perlu disertai dengan deksripsi yang jelas sehingga suatu yang abstrak/kompleks tersebut dapat ditelaah secara lebih konkret/sederhana oleh siswa.Video pembelajaran dapat diartikan sebagai media yang digunakan untuk merangsang pikiran, perasaan dan kemauan siswa untuk belajar melalui penayangan ide atau gagasan, pesan dan informasi secara audio visual sehingga data mendukung terciptanya kualitas pembelajaran yang diharapkan.

Mempelajari mata pelajaran memerlukan pemahaman dan visualisasi untuk memproses isyarat digital. Multimedia interaktif merupakan bentuk kombinasi grafik, teks, suara, video, dan animasi. Penggabungan ini dapat menghadirkan pembelajaran dalam bentuk yang menyenangkan, menarik, mudah di mengerti dan jelas. Informasi akan mudah di mengerti karena sebanyak mungkin indera, terutama telinga dan mata, digunakan untuk menyerap informasi.

Kegunaan atau manfaat media dalam proses pembelajaran adalah video pembelajaran dapat diartikan sebagai media yang digunakan untuk merangsang pikiran, perasaan dan kemauan siswa untuk belajar melalui penayangan ide atau gagasan, pesan dan informasi secara audio visual sehingga data mendukung terciptanya kualitas pembelajaran yang diharapkan. Tematik adalah salah satu mata pelajaran yang sangat berperan dalam bidang studi lain, diharapkan siswa akan lebih menghargai pentingnya Tematik dan berminat mempelajarinya. Dalam upaya pencapaian tujuan pengajaran pendidikan Tematik, perlu adanya suatu proses yang aktif sehingga dapat memotivasi siswa untuk belajar Tematik dan meningkatkan prestasinya. Jadi tujuan pengajaran bukanlah tujuan sesaat, melainkan suatu 
kerja sama yang baik di segala aspek secara berkesinambungan.

Tematik adalah gabungan ilmu pasti, nalar dan imajinasi dengan langkah-langkah pengerjaan yang jelas dan terpadu. Siswa yang berhalangan masuk dikarenakan ijin, bisa saja tertinggal dalam mengikuti pelajaran Tematik, juga siswa yang terlambat memahami materi akan kesulitan untuk memahami materi berikutnya yang berkaitan. Hal ini sangat merugikan siswa dan mempengaruhi prestasi yang dicapai siswa. Pada akhirnya yang menjadi permasalahan dalam pengabdian ini adalah bagaimana implementasi dan kelayakan video pembelajaran pada mata pelajaran Tematik tahun pelajaran 2015/2016 yang dikembangkan di tempat Mitra.

Dalam kegiatan pengajaran, guru: a) mengkondisikan suasana belajar yang menyenangkan. b) mendiskusikan kompetensi yang sudah dipelajari dan dikembangkan sebelumnya berkaitan dengan kompetensi yang akan dipelajari dan dikembangkan; c) menyampaikan kompetensi yang akan dicapai dan manfaatnya dalam kehidupan sehari-hari; dan d) menyampaikan garis besar cakupan materi dan kegiatan yang akan dilakukan. e) menyampaikan lingkup dan teknik penilaian yang akan digunakan.

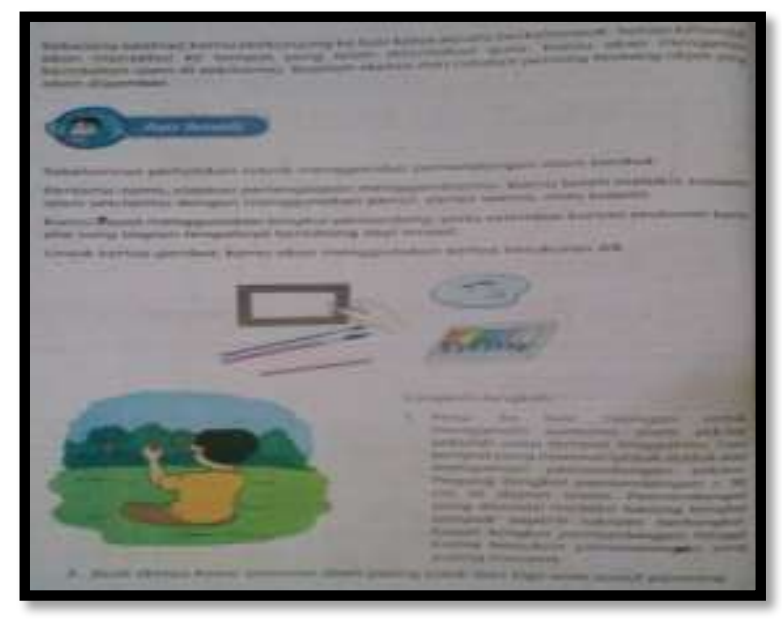

Gambar 1.

Contoh Materi dan Soal Tematik dari Literatur Kelas V

Model ini tersusun secara sistematis sesuai dengan urutan-urutan kegiatan dalam upaya pemecahan masalah belajar sesuai dengan kebutuhan dan karakteristik siswa terutama siswa di SD mitra yaitu dari tahap konsep atau pemilihan mata pelajaran, tahap desain, tahap pengumpulan materi, tahap pembuatan media, tahap validasi untuk mengukur kelayakan dari video pembelajaran ini hingga tahap distribusi yaitu penyaluran media kepada target sasaran (guru, siswa bahkan masyarakat luas).

\section{METODE KEGIATAN}

Pada pengabdian ini akan dihasilkan produk berupa VCD animasi yang dapat membantu siswa Sekolah Dasar dalam belajar. Untuk itu VCD animasi ini harus dibuat oleh guru yang menguasai pelajaran yang diampunya. Para guru ini harus dilatih terlebih dahulu, agar dapat membuat VCD pembelajaran. Tahapan pelatihan pembuatan animasi pembelajaran sebagai berikut :

a. Pelatihan Pengenalan Grafis

b. Pelatihan Pengenalan Animasi

c. Pelatihan Animasi Multimedia

d. Pelatihan Pengemasan VCD

Setelah para guru dilatih, maka dibentuk grup kecil untuk membuat VCD Pembelajaran Sekolah Dasar. Dalam pembuatan VCD ini, para guru tetap didampingi oleh para Instruktur Pelatihan.

Setelah pembuatan VCD pembelajaran Sekolah dasar selesai, VCD ini akan dipublikasikan melalui website Marketing, agar dapat luas jangkauannya.

\section{HASIL DAN PEMBAHASAN}

\section{Pembukaan Pelatihan Multimedia Learning untuk Sekolah Dasar}

Pelatihan dilaksanakan di Sekolah Dasar Mohammad Hatta, J1. Simpang Flamboyan 30, Malang dan dibuka oleh kepala Sekolah Dasar Mohammad Hatta, Bapak Suyanto S.Pd, MK.Pd. Pelatihan ini diikuti oleh 25 orang guru yang berasal dari SDI Mohammad Hatta dan SD IISS Malang.

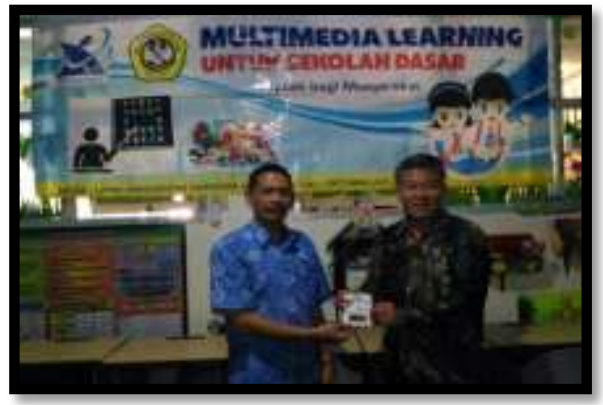

Gambar 2 Pembukaan Pelatihan Multimedia Learning untuk Sekolah Dasar 


\section{Pelatihan Pengenalan Grafis}

Pelatihan ini bertujuan untuk memperkenalkan cara memodifikasi gambar yang nanti akan digunakan untuk animasi atau dalam desain kemasan VCD. Pelatihan ini dilaksanakan pada tanggal 28 Mei 2017 dengan instruktur Bapak Ir. Haris Satriawan, S.Kom, MM. Bapak Haris adalah dosen Desain Grafis dari Universitas Merdeka Malang dan juga sebagai grafis desainer dan pengelola Unmer Print.

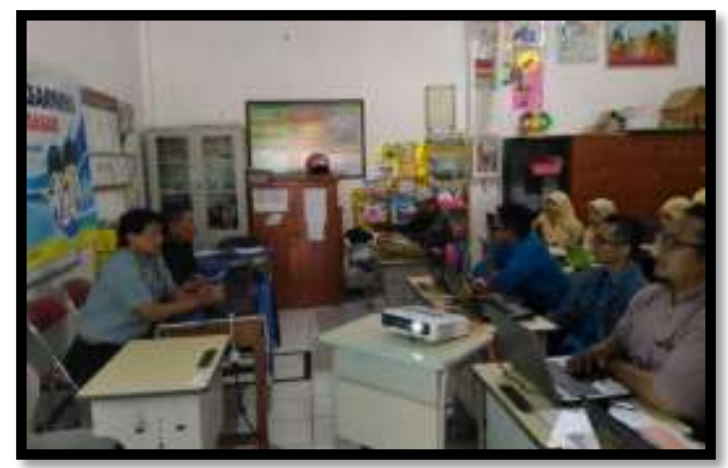

Gambar 3 Pelatihan Pengenalan Grafis

Pada pelatihan ini digunakan sofware Corel Draw sebagai tools untuk mendesain teks dan gambar agar menjadi tampilan yang menarik, seperti pada gambar berikut ini.

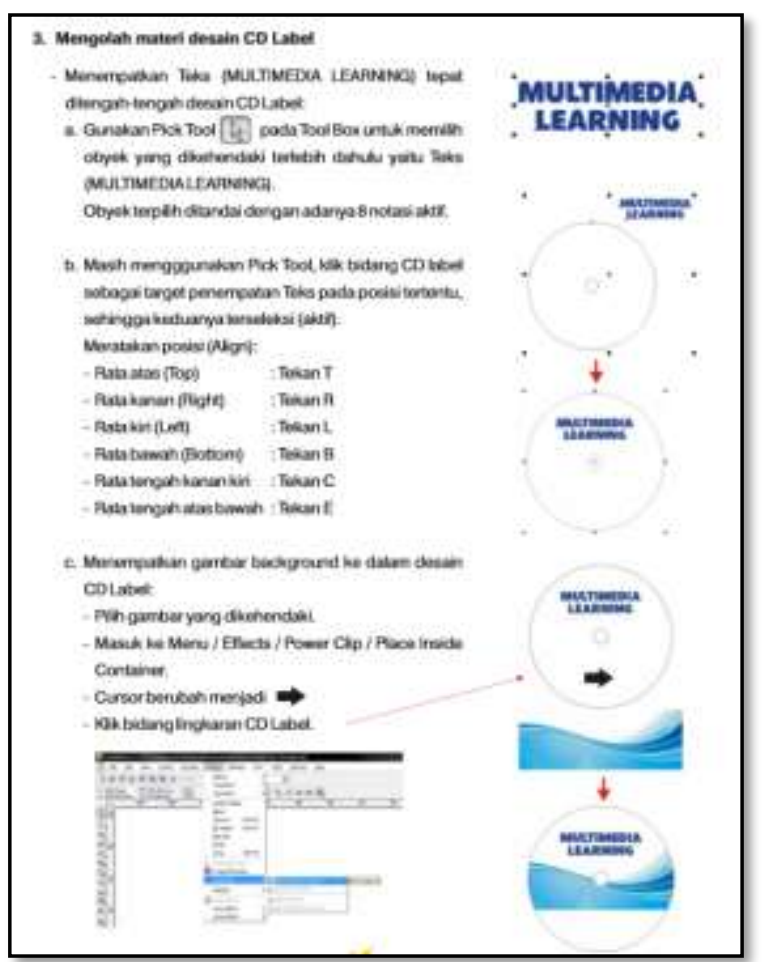

Gambar 4 Cuplikan Modul Pelatihan Pengenalan Grafis

\section{Pelatihan Pengenalan Animasi}

Pelatihan ini bertujuan untuk memperkenalkan langkah-langkah yang harus dilakukan dalam pembuatan Animasi. Pelatihan ini dilaksanakan pada tanggal 4 Juli 2017 dengan instruktur Bapak Ahmad Rofiqul Muslikh, S.Kom, M.Kom. Bapak Rofikul adalah dosen Animasi Komputer dari Universitas Merdeka Malang.

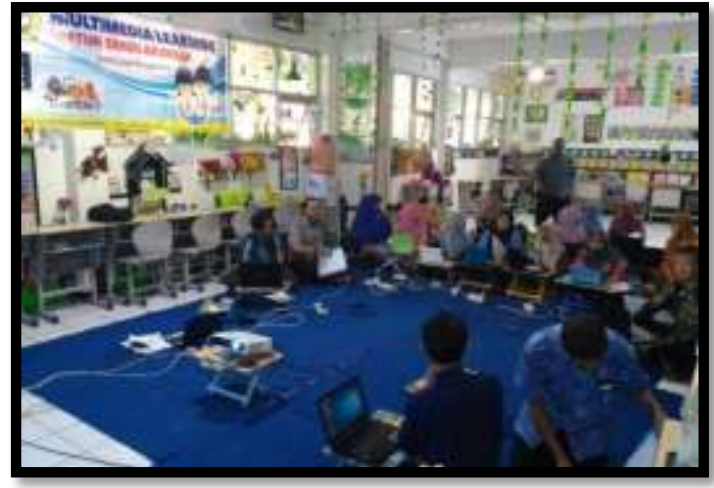

Gambar 5 Pelatihan Pengenalan Animasi

Pada pelatihan ini memperkenalkan software Adobe Flash Profesional sebagai tools untuk menganimasikan teks dan gambar agar menjadi suatu tampilan yang menarik, seperti pada gambar berikut ini :

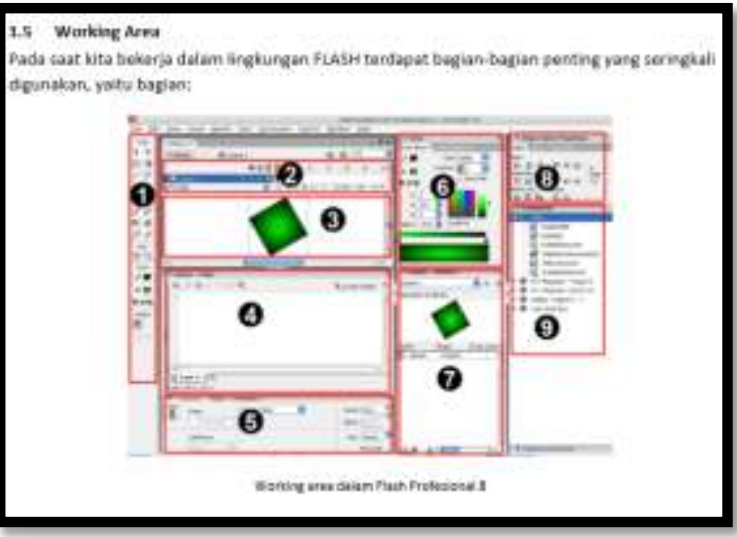

Gambar 6 Cuplikan Modul Pelatihan Pengenalan Animasi

\section{Pelatihan Animasi Multimedia}

Pelatihan ini merupakan lanjutan dari pelatihan Pengenalan Animasi, yang bertujuan membuat animasi komputer secara lengkap. Pelatihan ini dilaksanakan pada tanggal 11 Juli 2017 dengan instruktur Bapak Ahmad Rofiqul Muslikh, S.Kom, M.Kom. 


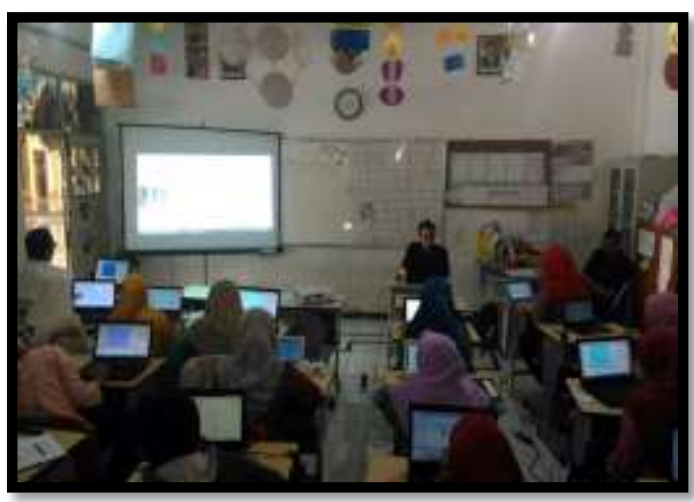

Gambar 7 Pelatihan Animasi Multimedia

Pada pelatihan ini menggunakan video tutorial untuk mempermudah para guru menggunakan software Adobe Flash dalam menganimasikan teks dan gambar, seperti pada gambar berikut ini

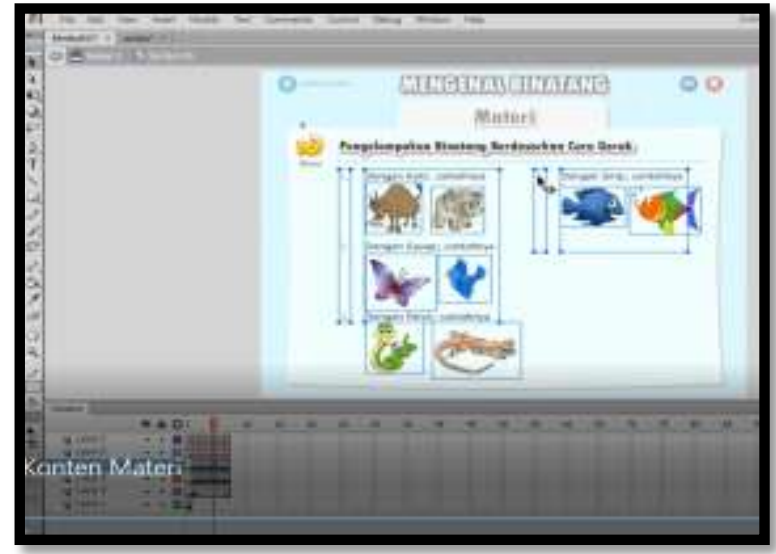

Gambar 8 Tutorial Pelatihan Animasi Multimedia

\section{Pelatihan Pengemasan VCD}

Pelatihan ini bertujuan untuk membuat kemasan VCD agar menarik tampilannya untuk dipasarkan. Pelatihan ini dilaksanakan pada tanggal 18 Juli 2017 dengan instruktur ibu Elta Sonalitha, S.Kom., MT. Ibu Elta adalah dosen E-Bisnis dari Universitas Merdeka Malang.

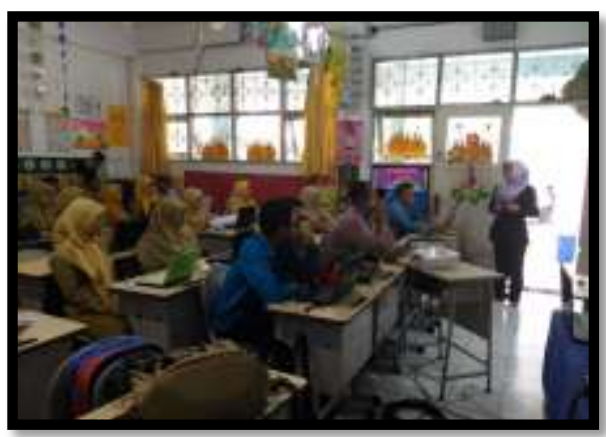

Gambar 9 Pelatihan Pengemasan VCD

\section{Hasil Pelatihan}

Dari pelatihan yang dilaksanakan dihasilkan sebuah VCD animasi pembelajaran sederhana yaitu Pembelajaran Mengenal Binatang. Tampilan dari animasi pembelajaran sebagai berikut :

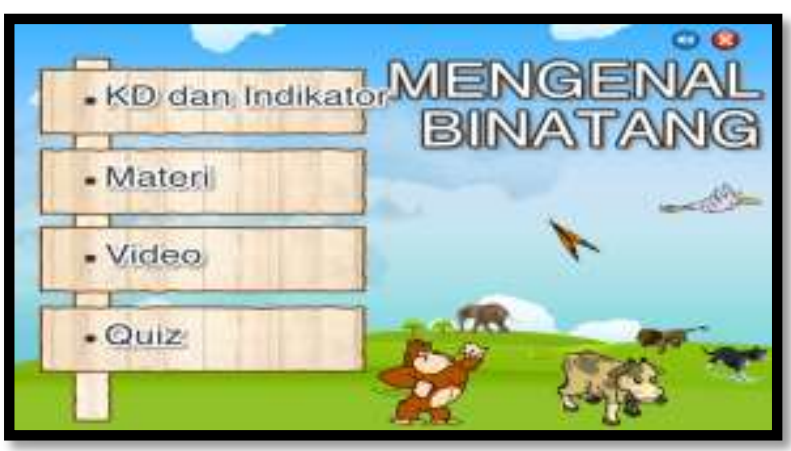

Gambar 10 Menu Utama Pembelajaran Mengenal Binatang

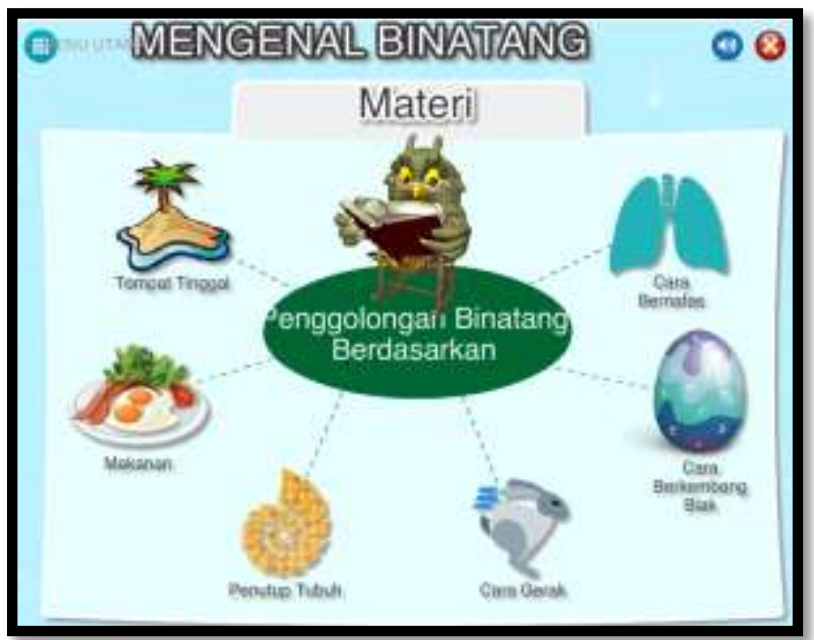

Gambar 11 Menu Materi Pembelajaran Pengenalan Binatang

\section{KESIMPULAN}

Dari Pelaksanaan pengabdian masyarakat yang telah dilaksanakan ini, dapat disimpulkan :

a. Para guru sekolah dasar dapat dilatih untuk membuat Video Pembelajaran sesuai dengan pelajaran yang diampu

b. Para guru dapat memperkaya isi dari VCD Animasi Pembelajaran sesuai dengan pelajaran yang diampu.

\section{PENGHARGAAN}

Terima kasih disampaikan kepada Dirjen Dikti melalui Direktorat Penelitian dan Pengabdian Kepada Masyarkat (DP2M) yang telah mendanai pengabdian kepada masyarakat melalui program IbM tahun anggaran 2017. 


\section{REFERENSI}

http://www.m-edukasi.web.id

http://www.smartedumedia.com

https://dspace.stir.ac.uk/bitstream/1893/458/1/Plow man\%20BJET.pdf

Karina, Dwi Putri. Pengembangan Multimedia Pembelajaran Interaktif untuk Mata Pelajaran Teknik Digital di SMK Muhammadiyah 3 Yogyakarta.
Soetomo, Pemberdayaan Masyarakat, Pustaka Pelajar, Jogyakarta, 2011

Venthy, Made Hendrawati. Pengembangan Video Pembelajaran dengan Model Pembelajaran Berbantuan Komputer (PBK) dalam Mata Pelajaran Matematika pada Siswa Kelas IV Semester Ganjil Tahun Pelajaran 2012/2013 di SD Negeri 4 Bebetin 